\title{
Treatment-Related Mortality With Everolimus in Cancer Patients
}

\author{
Robert Wesolowski, Mahmoud Abdel-Rasoul, Maryam lustberg, Maria Paskell, Charles L. Shapiro, Erin R. Macrae \\ The James Cancer Hospital and Richard Solove Research Institute, The Ohio State University Comprehensive Cancer Center, Columbus, \\ Ohio, USA \\ Disclosures of potential conflicts of interest may be found at the end of this article.
}

Key Words. Everolimus • Meta-analysis • Cancer • Mortality • Adverse events

\begin{abstract}
Introduction. The overall incidence and odds of fatal adverse events (FAEs) after exposure to everolimus are not well defined. We performed a comprehensive meta-analysis of published randomized controlled trials (RCTs) to determine the role of everolimus in treatment-related mortality in patients with cancer. Methods. PubMed databases and abstracts from the proceedings of the American Society of Clinical Oncology and the San Antonio Breast Cancer Symposium were searched for RCTs of everolimus either alone or in combination with another agent compared with the control arm without everolimus and that reported deaths from an adverse event from January 1966 to July 2013. The primary objective was to determine the difference of FAEs between everolimustreated patients and control group patients.
\end{abstract}

Results. In total, 2,997 patients with multiple solid tumors from nine RCTs were included. The overall incidence of FAEs in cancer patients treated with everolimus was $0.7 \%(95 \% \mathrm{Cl}$ $0.3 \%-1.1 \%)$ compared with $0.4 \%(95 \% \mathrm{Cl} 0.0 \%-0.7 \%)$ in cancer patients who did not receive everolimus. The odds ratio of FAEs was greater in everolimus-treated patients (Peto odds ratio $=3.80,95 \% \mathrm{Cl} 1.59-9.07, p=.003$ ). In subgroup analyses, no significant difference was found in the incidence or odds of FAEs by everolimus administration (alone or in combination) or tumor type (breast cancer vs. nonbreast cancer; $p=.63$ ).

Conclusion. In patients with cancer, everolimus is associated with a small but significant increase in the odds of a treatmentrelated fatal events. The Oncologist 2014;19:661-668

Implications for Practice: This meta-analysis reviewed published or presented randomized clinical trials with everolimus alone or in combination versus control treatment or placebo in patients with solid tumors. It found a small but statistically significant increase in fatal adverse events among everolimus treated patients $(0.4 \%$ vs. $0.7 \%$ in control vs. everolimus arm, $p=.003)$. This suggests that fatal adverse events are rare in cancer patients treated with everolimus. However, oncologists should be aware of a small increase in the risk of death from everolimus and therefore select patients carefully for this therapy, and monitor as well as manage everolimus related toxicities aggressively.

\section{INTRODUCTION}

Everolimus is an oral inhibitor of the mammalian target of rapamycin (mTOR) and has demonstrated antitumor activity across multiple types of advanced malignancies including breast cancer, renal cell carcinoma, angiolipoma, neuroendocrine cancer, and central nervous system tumors [1]. Everolimus received U.S. Food and Drug Administration (FDA) approval in a variety of cancer-related indications and is routinely used in oncology practices as an alternative to traditional cytotoxic chemotherapy. Serious adverse events such as stomatitis, anemia, pulmonary toxicity, hyperglycemia, and myelosuppression are commonly reported. However, the overall impact of these off-target effects is largely unknown.

An adverse event is defined by the FDA and by the National Cancer Institute as any untoward medical occurrence associated with the use of a drug in humans, whether or not it is considered drug related [2]. A fatal adverse event (FAE) is further classified as a death thought to be caused in all likelihood by a pharmaceutical agent [2]. The incidence of FAEs is low overall, occurring in $0.3 \%$ of prospective clinical trials, but it is an important iatrogenic cause of hospitalizations and mortality in the U.S. $[3,4]$. Patients with cancer may be at higher risk of FAEs because of toxicities associated with traditional chemotherapy [5]. Given the known risk of these serious complications associated with oncologic therapies, FAEs can be underreported in clinical trials using targeted agents, and investigation into the true incidence of these events is warranted [6].

A recent meta-analysis of mTOR inhibitors has shown a near doubling in the relative risk of FAEs compared with control arms [7]. FAEs occurring with everolimus administration have been sporadically reported in the large randomized

Correspondence: Erin R. Macrae, M.D., The James Cancer Hospital, The Ohio State University Comprehensive Cancer Center, B407 Starling Loving Hall, 320 West 10th Avenue, Columbus, Ohio 43210, USA. Telephone: 614-366-8541; E-Mail: erin.macrae@osumc.edu Received September 8, 2013; accepted for publication February 26, 2014; first published online in The Oncologist Express on May 2, 2014. @AlphaMed Press 1083-7159/ 2014/\$20.00/0 http://dx.doi.org/10.1634/theoncologist.2013-0355 
controlled trials (RCTs) using everolimus in patients with cancer, although no definitive conclusions regarding the incidence of these events with everolimus alone have been established. This topic is of particular importance as everolimus continues to gain momentum in the oncology community as an active agent across increasing numbers of tumor subtypes. In this report, we investigate the incidence and odds ratios of FAEs in an up-to-date, comprehensive metaanalysis of published RCTs using everolimus in patients with cancer.

\section{METHODS}

\section{Selection of Studies}

PubMed citations were reviewed from January 1966 to July 2013. The search criteria were clinical trials published in English and the key words were everolimus (as well as the trade name Afinitor) and cancer. Abstracts from the American Society of Clinical Oncology (ASCO) and the San Antonio Breast Conference Symposium (SABCS) were also reviewed. When more than one publication or presentation was identified from the same clinical trial, the most recent report with complete information about fatal adverse events was included for analysis. The most recent package insert of everolimus was also accessed to identify relevant information. Efforts were made to contact investigators and the manufacturer of everolimus when relevant data were unclear. The quality of reports of clinical trials was assessed and calculated using the seven-item Jadad scale including randomization, double-blinding, and withdrawals [8].

\section{Data Extraction and Clinical Endpoints}

Data abstraction was conducted independently by three investigators (R.W., M.L., E.R.M.) according to the Preferred Reporting Items for Systematic Reviews and Meta-Analyses statement [9]. Any discrepancies were resolved by consensus. For each study, we extracted the following information: first author's name, year of publication, trial phase, whether the trial was blinded, number of enrolled patients, treatment arms, duration and schedule of everolimus therapy (including other antineoplastic agents if everolimus was used in combination), median follow-up, underlying malignancy, and the number and causes of author-reported deaths during the study and their attributions to the study regimen. FAEs are defined by the National Cancer Institute's Common Terminology Criteria for Adverse Events (CTCAE) as deaths occurring during a clinical trial as a result of exposure to an experimental drug. FAEs are defined in versions 2, 3, and 4 of the CTCAE as grade 5 events. CTCAE versions 3 and 4 require that the cause of an FAE be specified, whereas version 2 does not [10]. All deaths occurring within 1 month of discontinuation of a study drug are required to be reported regardless of whether they were related to an adverse event.

The primary goal of this study was to establish the association of everolimus with FAEs in cancer patients. Therefore, only RCTs with a direct comparison between everolimus either alone or in combination with another anticancer agent (i.e., chemotherapy, hormonal or targeted therapy) to a control arm were included. Trials that met the following criteria were chosen for analysis: prospective phase II or phase III trials that included cancer patients, randomly assigned study subjects to everolimus treatment alone or in combination with an anticancer agent or control arm without everolimus, and contained adequate reporting data regarding deaths for which an adverse event was the primary cause.

\section{Statistical Analysis}

For the calculation of incidence, we extracted the FAEs and the total number of patients treated with the study drug from the selected clinical trials. The proportion of patients who died and the $95 \%$ confidence intervals ( $\mathrm{Cls}$ ) were derived from each trial. We calculated the Peto odds ratio (OR) and $\mathrm{Cl}$ of mortality related to the study drug in patients assigned to everolimus versus controls in the same trial. Cause of death and attribution to trial agent(s) were collected when reported.

The pooled estimates for the main effect and subgroup analyses were calculated from fixed effects models and reported using the Peto one-step method [11]. Peto odds ratios were used because at event rates below $1 \%$, the Peto one-step odds ratio method is found to be the least biased and most powerful. It provides the best confidence interval coverage, provided that there is no substantial imbalance between treatment and control group sizes within studies and treatment effects are not exceptionally large $[12,13]$. In the case of rare events, methods such as the inverse variance method should be avoided [12]. As a sensitivity analysis, we also compared our results using the Mantel-Haenszel fixed and random effects models estimating odds ratios and relative risks. We assessed statistical heterogeneity among trials included in the meta-analysis using the Cochran $Q$ statistic, and inconsistency was quantified with the $I^{2}$ statistic that estimates the percentage of total variation across studies due to heterogeneity rather than chance [14]. We considered an $I^{2}$ value $>50 \%$ as indicative of substantial heterogeneity.

Prespecified subgroup analysis was performed to identify risk factors for death with everolimus-based therapy. We examined a possible dose-administration relationship between everolimus and death after administration by dividing trials into those in which everolimus was given in combination or alone. Subgroup analysis was also performed by tumor type (breast vs. nonbreast). To test the variation in risk estimates by everolimus administration and tumor subtypes, we conducted meta-regression analyses [15].

Finally, publication bias was evaluated through funnel plots and with Begg's and Egger's tests $[16,17]$. A two-tailed $p$ value of $<.05$ was considered statistically significant. Statistical analyses were performed using RevMan 5.2 (The Cochrane Collaboration, Copenhagen, Denmark, http://www. cochrane.org) and Stata/SE version 11.0 software (StataCorp, College Station, TX, http://www.stata.com) [18].

\section{RESULTS}

\section{Population Characteristics}

The original search yielded a total of 364 potentially relevant everolimus studies: 120 abstracts from PubMed and 244 from ASCO and SABCS meetings. The detailed selection process is presented in Figure 1. After evaluating each study, we initially excluded 336 studies. The remaining 28 studies were carefully screened and an additional 12 trials were excluded as 


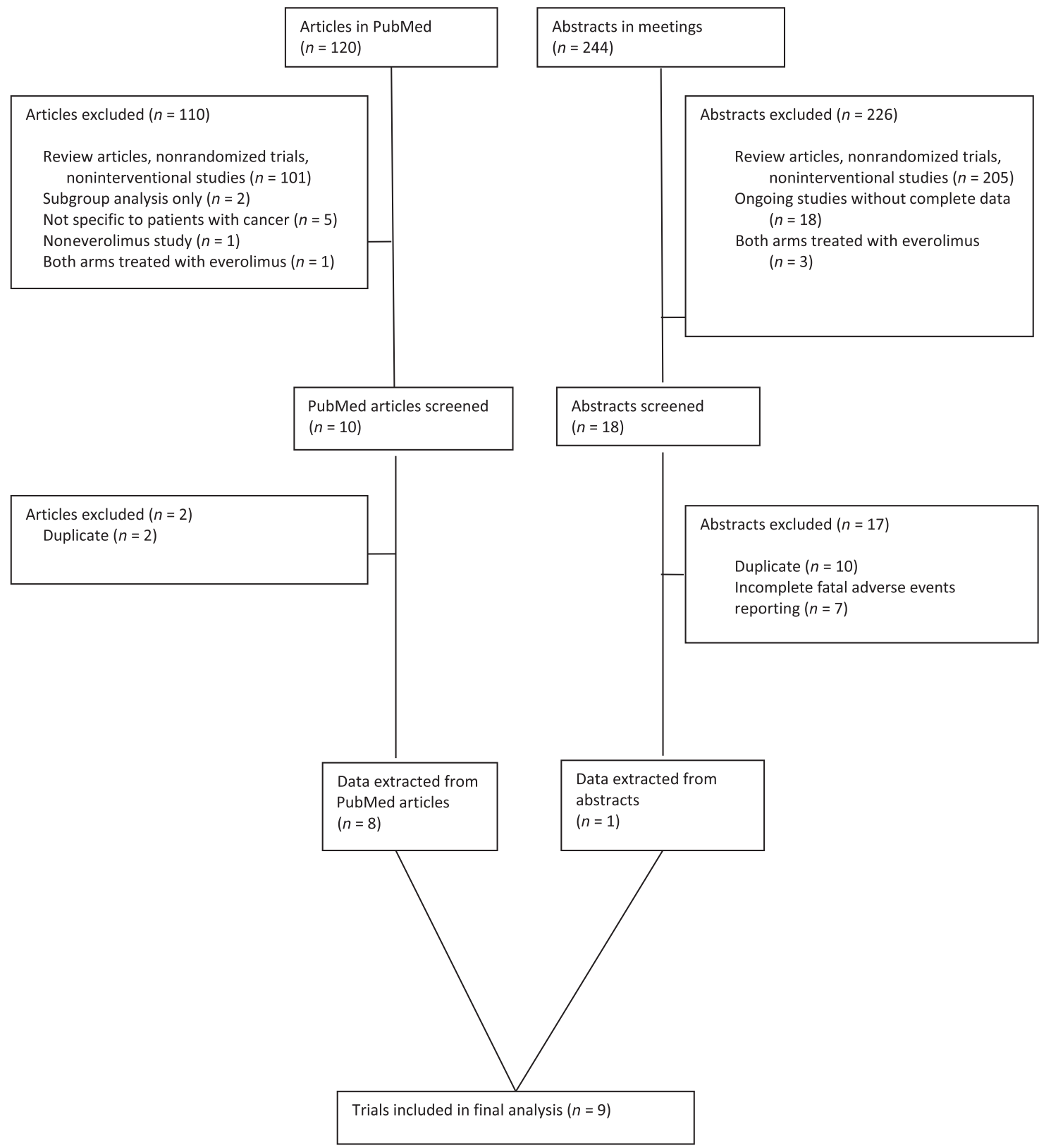

Figure 1. Selection process for the randomized controlled trials included in the meta-analysis.

duplicates. Sixteen of the remaining studies were thoroughly evaluated and 7 trials were excluded because of lack of $F A E$ reporting [19-25]. The abstracts for the BOLERO-3 and RECORD-3 trials presented only the percentage of FAEs in each arm and did not report the actual number of deaths and were therefore excluded $[22,25]$. Nine trials were selected for inclusion in the meta-analysis (Table 1) [26-35]. The GeparQuinto trial published a report on a planned interim safety analysis of 45 patients [31]. The final report on all 270 patients treated with everolimus was presented at the SABCS 2011 meeting [32]. Safety data from this study were verified with the primary author on all enrolled patients, and the number of FAEs was the same as that reported in the published interim safety analysis.

In total, 2,997 patients were available for the metaanalysis. Baseline characteristics of each trial are presented in Table 1. All selected trials included patients with a cancer diagnosis. Underlying malignancies included breast cancer, renal cell carcinoma, neuroendocrine tumors, angiolipomas, and subependymal giant cell astrocytomas. In these trials, patients were required to have adequate baseline organ and hematologic function, as well as good performance status. In all studies, patients were randomly assigned to either a control or everolimus group. Everolimus was administered alone in four studies and compared with placebo [26, 28, 33, 34]. Anticancer agents given with everolimus included long-acting octreotide [27], endocrine therapy, or chemotherapy [29-32, 35]. Everolimus was administered at a dose of $10 \mathrm{mg}$ daily in all but two studies [31-33]. In the GeparQuinto study, everolimus dose was gradually titrated to $5 \mathrm{mg}$ daily; in the EXIST-1 study, everolimus was administered at a starting dose of $4.5 \mathrm{mg} / \mathrm{m}^{2}$ and adjusted to achieve and maintain everolimus trough concentrations of $5 \mathrm{ng} / \mathrm{mL}$ to $15 \mathrm{ng} / \mathrm{mL}$ as tolerated [33]. 
Table 1. Characteristics of the randomized control trials included in the meta-analysis

\begin{tabular}{|c|c|c|c|c|c|c|c|}
\hline Source (trial name) & Phase & $\begin{array}{l}\text { Crossover } \\
\text { allowed }\end{array}$ & $\begin{array}{l}\text { Participants } \\
\text { enrolled }(n)\end{array}$ & $\begin{array}{l}\text { Participants for } \\
\text { analysis }(n)\end{array}$ & $\begin{array}{l}\text { Median follow-up, } \\
\text { months (range) }\end{array}$ & $\begin{array}{l}\text { Underlying } \\
\text { malignancy }\end{array}$ & $\begin{array}{l}\text { Study } \\
\text { quality }^{\mathrm{a}}\end{array}$ \\
\hline $\begin{array}{l}\text { Motzer et al., } 2010 \text { (RECORD-1) } \\
\text { [26] }\end{array}$ & III & Yes & 416 & & 13 (NR) & $\begin{array}{l}\text { Renal cell } \\
\text { carcinoma }\end{array}$ & 4 \\
\hline Everolimus 10 mg daily & & & & 277 & & & \\
\hline Placebo & & & & 139 & & & \\
\hline $\begin{array}{l}\text { Pavel et al., } 2011 \text { (RADIANT-2) } \\
\text { [27] }\end{array}$ & III & Yes & 429 & & 28 (NR) & $\begin{array}{l}\text { Neuroendocrine } \\
\text { carcinoma with }\end{array}$ & 5 \\
\hline $\begin{array}{l}\text { Everolimus } 10 \text { mg daily + } \\
\text { LAR } 30 \text { mg every } 28 \text { days }\end{array}$ & & & & 216 & & $\begin{array}{l}\text { carcinoid } \\
\text { syndrome }\end{array}$ & \\
\hline
\end{tabular}

Placebo + LAR 30 mg every 28 days
Yao et al., 2011 (RADIANT-3)

[28]

Everolimus $10 \mathrm{mg}$ daily

Placebo

Baselga et al., 2009 (JCO 2009)

[29]

Everolimus $10 \mathrm{mg}+$ letrozole

$2.5 \mathrm{mg}$

Placebo + letrozole $2.5 \mathrm{mg}$ daily
III Yes 410

213
Baselga et al., 2012 (BOLERO-2) III No 724 [30]

Everolimus $10 \mathrm{mg}$ daily + exemestane $25 \mathrm{mg}$ daily

Placebo + exemestane $10 \mathrm{mg}$ daily

von Minckwitz et al., 2011

(GeparQuinto) $^{\mathrm{C}}[31,32]$

Everolimus $5 \mathrm{mg}$ daily ${ }^{\mathrm{d}}+$ paclitaxel $^{\mathrm{e}} 80 \mathrm{mg} / \mathrm{m}^{2}$ weekly

Paclitaxel $80 \mathrm{mg} / \mathrm{m}^{2}$ weekly

III No

Franz et al., 2013 (EXIST-1)

[33]

Everolimus $4.5 \mathrm{mg} / \mathrm{m}^{2}$

daily $^{\dagger}$

Placebo

Bissler et al., 2013 (EXIST-2)

[34]

Everolimus $10 \mathrm{mg}$ daily

Placebo

Bachelot et al., 2012 (GINECO)

[35]

Everolimus $10 \mathrm{mg}$ daily +

tamoxifen $20 \mathrm{mg}$ daily

Tamoxifen 20 mg daily
17 (NR)

207

203

270

724

402

201

201

III Yes 117

117

9.7 (NR)

SEGA associated 5 with TSC

78

39

III $\quad$ Yes $\quad 118$

79

39

111
Pancreatic neuroendocrine

Operable breast 4 cancer carcinoma
$12.5(\mathrm{NR})$

Metastatic

breast cancer

NR

38

32

NR $\quad \begin{aligned} & \text { Operable breast } 2 \\ & \text { cancer }\end{aligned}$

4

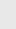




\section{Incidence of FAEs}

Among the nine trials included in this analysis, four studies reported no FAEs in control or treatment arms [27, 29, 33, 35]. The GINECO study reported one death in the control arm that was not related to an adverse event as confirmed by the principal investigator [35]. Five trials had at least one FAE in either the treatment or control arm [26, 28, 30-32, 34]. For the 1,735 patients who received everolimus, 20 died in association with an adverse event. When we used fixed effects modeling for this analysis (heterogeneity test: $p=.235 ; l^{2}=23.0 \%$ ), we found that the overall incidence of mortality with everolimus was $0.7 \%(95 \% \mathrm{Cl} 0.3 \%-1.1 \%$, $p<.001)$. For the control group, there were two deaths among 1,262 patients in the nine studies that reported FAEs, which conferred an incidence of $0.4 \%(95 \% \mathrm{Cl} 0.0 \%-0.7 \%$, $p=.034$; heterogeneity test: $p=.998 ; l^{2}=0.0 \%$; Table 2 ) $[28,30]$.

\section{Main Effect of Everolimus Administration on FAEs}

We determined the overall Peto odds ratio of an FAE from the nine RCTs reporting FAEs. The odds of FAEs with everolimus were 3.80 (95\% Cl 1.59-9.07, $p=.003$ ) times greater than the odds of FAEs in patients who did not receive everolimus. No significant heterogeneity among the included trials was observed ( $p=.98 ; l^{2}=0.0 \%$; Figure 2 ). The estimate obtained using the one-step Peto method differed minimally from estimates obtained using Mantel-Haenszel fixed or random effects methods $(\mathrm{OR}=4.18,95 \% \mathrm{Cl} 1.33-12.89$ and $\mathrm{OR}=3.96$, $95 \% \mathrm{Cl}$ 1.26-12.45, respectively).

\section{Specific Causes of Death Related to FAEs}

We investigated the prevalence of specific causes of death from an FAE secondary to everolimus administration. The proportion of deaths directly attributed to everolimus was reported in only one trial [28]. In the 20 patients treated with everolimus with FAEs, the most common causes of death included infection ( $n=8,40 \%)$, cardiopulmonary failure ( $n=4,20 \%)$, and renal failure $(n=2,10 \%)$. One patient in the RECORD-1 study was reported to have both sepsis and pneumonia [26]. Both of these were combined into one event. Other causes of death were each reported in a single patient and included hepatic failure [28], convulsions [34], cerebral vascular accident [30,29], tumor hemorrhage [30], and suicide [30]. One patient death in the everolimus group had unknown cause [28]. In 8 patients who died of infection, sepsis was cited as the most common cause $(n=5,62.5 \%)[26,28,30]$, followed by pneumonia ( $n=3,37.5 \%$; 1 patient in the RECORD-1 study had sepsis and pneumonia) $[26,28,30]$ and bronchopulmonary aspergillosis ( $n=1,12.5 \%$ ) [26]. It is of note that in 1 patient who died of sepsis, candida pneumonia was cited as the source infection leading to acute respiratory distress syndrome [26]. One patient with cardiopulmonary failure had grade 3 everolimus-related interstitial lung disease [26]. For the patient death secondary to convulsions as the adverse event, investigators reported the cause less likely to be directly related to everolimus [34]. We included this occurrence in our analysis because it was reported as an adverse event. Causes of FAEs in control arms included pneumonia [30] and pulmonary embolism [28].

\section{Influence of Tumor Type or Administration of Everolimus}

In a preplanned analysis, we examined the effect of everolimus administration or tumor type on ORs of FAEs. Four studies were in breast cancer patients [29-32,35], and five studies included nonbreast cancer diagnoses [26-28, 33, 34]. Five studies used everolimus in combination [27, 29-31, 35], and everolimus was administered alone in the remaining four trials $[26,28,33,34]$. Because only five trials had FAEs, the distribution of studies by tumor type and everolimus administration was the same (Table 2) [26, 28, 30, 31, 34]. Generally, everolimus was administered in combination with another drug in the breast cancer trials, and it was given as a single agent in nonbreast cancer trials, with the exception of RADIANT-2 in which no FAEs occurred [27]. Therefore, we were unable to determine the Peto OR of FAEs by tumor type or type of everolimus administration independently. The Peto OR of FAEs in breast cancer trials in which everolimus was given in combination with another anticancer agent was 2.91 (95\% Cl 0.73-11.64) compared with 4.51 (95\% Cl 1.48-13.82) in studies with patients with nonbreast cancer malignancies in which everolimus was administered as a single agent. There was no significant difference in patient deaths in either category by meta-regression analysis $(p=.56)$.

\section{Quality of the Study and Publication Bias}

All trials included in the meta-analysis were randomized, multicenter, open-label, phase III trials published in peerreviewed journals. Each trial contained a control arm in which patients were not administered everolimus. No evidence of publication bias was detected for the odds of an FAE by everolimus administration in cancer patients by Egger's test ( $p=.332)$ or Begg's test $(p=.99)$.

\section{Discussion}

To our knowledge, this is the largest and most current report to show a significant increase in the treatment-related mortality with the use of everolimus in cancer patients. The incidence of FAEs with everolimus was $0.7 \%(95 \% \mathrm{Cl} 0.3 \%-1.1 \%)$. Despite the low absolute incidence, there is an almost fourfold increase overall in the odds of death with therapy in everolimustreated patients compared with controls.

Stratified analyses were performed to evaluate subgroups with the potentially higher incidence of dying while on everolimus therapy. No differences were found between tumor subtypes, and similarly, no differences were noted between everolimus monotherapy or in combination with another agent. This remains a hypothesis-generating analysis, and caution should be used when interpreting these subgroups because of the limited sample size.

Death on everolimus therapy has been reported in large clinical trials, and a recent meta-analysis of $\mathrm{mTOR}$ inhibitors by Choueiri et al. found an increased risk of fatal drug-related death in patients receiving everolimus or temsirolimus compared with controls [7]. All everolimus trials that were analyzed by Choueiri et al. were included in our meta-analysis. However, our study also analyzed additional data from the GeparQuinto, GINECO, EXIST-1, and EXIST-2 trials, which were not included in the publication by Choueiri et al. These trials were not included in their analysis perhaps because published 
Table 2. Incidence and Peto odds ratio of fatal adverse events stratified by tumor type and everolimus administration

\begin{tabular}{|c|c|c|c|c|c|c|c|c|c|c|c|c|}
\hline \multirow[b]{3}{*}{ Treatment } & \multirow{3}{*}{$\begin{array}{l}\text { Total number } \\
\text { of trials } \\
\text { [reference] }\end{array}$} & \multirow[b]{3}{*}{$\begin{array}{l}\text { Number of included } \\
\text { trials [reference] }\end{array}$} & \multicolumn{4}{|c|}{ Everolimus arm } & \multicolumn{4}{|c|}{ Control arm } & \multicolumn{2}{|r|}{ Overall } \\
\hline & & & \multicolumn{2}{|c|}{$\begin{array}{c}\text { Number of } \\
\text { patients }\end{array}$} & \multicolumn{2}{|c|}{ Incidence } & \multicolumn{2}{|c|}{$\begin{array}{c}\text { Number of } \\
\text { patients }\end{array}$} & \multicolumn{2}{|c|}{ Incidence } & \multicolumn{2}{|c|}{ Peto OR of FAEs } \\
\hline & & & FAEs & Total & (\%) & $95 \% \mathrm{Cl}$ & FAEs & Total & (\%) & $95 \% \mathrm{Cl}$ & OR & $95 \% \mathrm{Cl}$ \\
\hline \multicolumn{13}{|l|}{ Tumor type ${ }^{a}$} \\
\hline Breast & $4[29-32,35]$ & $2[30-32]$ & 8 & 878 & 0.7 & $0.2-1.3$ & 1 & 629 & 0.3 & $0.0-0.8$ & 2.91 & $0.73-11.64$ \\
\hline Nonbreast & $5[26-28,33,34]$ & $3[26,28,34]$ & 12 & 857 & 0.6 & $0.1-1.2$ & 1 & 633 & 0.4 & $0.0-0.8$ & 4.51 & $1.48-13.82$ \\
\hline \multicolumn{13}{|l|}{$\begin{array}{l}\text { Everolimus } \\
\text { administration }^{a}\end{array}$} \\
\hline Alone & $4[26,28,33,34]$ & $3[26,28,34]$ & 12 & 641 & 1.5 & $0.5-2.4$ & 1 & 420 & 0.5 & $0.0-1.2$ & 4.51 & $1.48-13.82$ \\
\hline In combination & $5[27,29-32,35]$ & $2[30-32]$ & 8 & 1094 & 0.5 & $0.1-0.9$ & 1 & 842 & 0.3 & $0.0-0.7$ & 2.91 & $0.73-11.64$ \\
\hline Overall $^{\mathrm{b}}$ & 9 & $5[26-28,33,34]$ & 20 & 1,735 & 0.7 & $0.3-1.11$ & 2 & 1,262 & 0.4 & $0.0-0.7$ & 3.80 & $1.59-9.07$ \\
\hline
\end{tabular}

The $p$ value for the difference in Peto OR by tumor type for FAEs $=.63$. The $p$ value for the difference by everolimus administration for FAEs $=.63$.

${ }^{a}$ Four studies were in breast cancer patients [29-32, 35], and five studies included nonbreast cancer diagnoses [26-28, 33, 34]. Five studies used everolimus in combination [27, 29-32, 35], and everolimus alone was administered alone in remaining four trials $[26,28,33,34]$.

$\mathrm{b}_{p}=.003$; heterogeneity test: $p=.98, I^{2}=0.0 \%$.

Abbreviations: $\mathrm{FAE}$, fatal adverse event; $\mathrm{Cl}$, confidence interval; $\mathrm{OR}$, odds ratio.

\begin{tabular}{|c|c|c|c|c|c|c|c|c|}
\hline \multirow[b]{2}{*}{ Study or Subgroup } & \multicolumn{2}{|c|}{ Experimental } & \multicolumn{2}{|c|}{ Control } & \multirow[b]{2}{*}{ Weight } & \multirow{2}{*}{$\begin{array}{l}\text { Peto Odds Ratio } \\
\text { Peto, Fixed, }(95 \% \mathrm{Cl})\end{array}$} & \multirow{2}{*}{\multicolumn{2}{|c|}{$\begin{array}{c}\text { Peto Odds Ratio } \\
\text { Peto, Fixed, }(95 \% \mathrm{Cl})\end{array}$}} \\
\hline & Events & Total & Events & Total & & & & \\
\hline Baselga et al. [29] & 0 & 138 & 0 & 132 & & Not estimable & & \\
\hline BOLERO-2 & 7 & 485 & 1 & 239 & $34.5 \%$ & $2.55(0.58-11.22)$ & & \\
\hline EXIST-1 & 0 & 78 & 0 & 39 & & Not estimable & & \\
\hline EXIST-2 & 1 & 79 & 0 & 39 & $4.4 \%$ & $4.45(0.07-287.23)$ & & \\
\hline GeparQuinto & 1 & 201 & 0 & 201 & $4.9 \%$ & $7.39(0.15-372.38)$ & & \\
\hline GINECO & 0 & 54 & 0 & 57 & & Not estimable & & \\
\hline RADIANT-2 & 0 & 216 & 0 & 213 & & Not estimable & & \\
\hline RADIANT-3 & 7 & 207 & 1 & 203 & $38.8 \%$ & $4.51(1.11-18.25)$ & & \\
\hline RECORD-1 & 4 & 277 & 0 & 139 & $17.4 \%$ & $4.54(0.56-36.52)$ & & \\
\hline Total $(95 \% \mathrm{Cl})$ & & 1,735 & & 1,262 & $100.0 \%$ & $3.80(1.59-9.07)$ & & \\
\hline Total events & 20 & & 2 & & & & & \\
\hline $\begin{array}{l}\text { Heterogeneity: } \chi^{2}= \\
\text { Test for overall effe }\end{array}$ & $\begin{array}{l}48, d f= \\
Z=3.01\end{array}$ & $\begin{array}{l}(p=.98 \\
p=.00\end{array}$ & $\begin{array}{l}\text { 3); } P=0 \\
\text { 3) }\end{array}$ & & & $\begin{array}{l}0.0 \\
\text { Fav }\end{array}$ & $\begin{array}{l}0.1 \\
\text { xperimental] }\end{array}$ & $\begin{array}{r}10 \\
\text { Favors [co }\end{array}$ \\
\hline
\end{tabular}

Figure 2. Peto odds ratio of fatal adverse events with everolimus versus control in patients with cancer.

Abbreviation: $\mathrm{Cl}$, confidence interval.

data were not yet available at the time of their manuscript preparation or some of the studies did not fit their eligibility criteria. Compared with our results, the investigators reported a higher incidence of death in the everolimus subgroup of $3.2 \%$ (95\% Cl 2.1\%-4.8\%). Importantly, the authors included all deaths within 30 days of exposure to experimental therapy in their analysis. In contrast, our study comprised deaths that were associated with an adverse event, which is less inclusive than the definition used in their analysis and likely accounts for the discrepancy. The incidence of FAEs in the control group was also larger in the meta-analyses by Choueiri et al. (1.2\% vs. $0.4 \%$ in our meta-analysis), which is consistent with the above differences in the trial design. The causes of drug-related death were similar in both meta-analyses, with infection being the primary cause. Acute renal failure was reported as the second most common cause by Choueiri et al. in contrast to our meta-analysis, which identified cardiopulmonary failure as the second most common cause followed by acute renal failure. The difference may be accounted for by the very small numbers of specific FAEs and exclusion of studies that used temsirolimus in our meta-analysis. In addition, in contrast to our analysis, Choueiri et al. also analyzed the FAE rate between trials that had longer duration on therapy (defined as greater than the median duration of treatment in all trials) versus those with shorter time on therapy. They found no difference in the incidence of FAEs between these studies.

Infection and pulmonary complications were the most cited cause of drug-related morality. The mechanisms behind everolimus-induced infectious complications are thought to be related to the drug's ability to inhibit T- and B-cell proliferation by blocking $G_{1}$ and $S$ phase transition in the cell cycle as well as inhibiting antibody production [36, 37]. Lung toxicity is mediated by an mTOR inhibitor's immune modulation leading to a noninfectious pneumonitis [38]. Biopsies performed in patients treated with everolimus-induced pneumonitis reveal organizing pneumonia with granulomatous inflammation, lymphocytic infiltration, and vasculitis [39]. The rates of everolimus-induced pneumonitis range between $<1 \%$ 
and $17 \%$ in various trials $[28,33,34]$. Treatment interruption, dose reductions, and treatment with corticosteroids are the most frequently cited management strategies of everolimusinduced pulmonary toxicities [39].

Everolimus utilization across the oncology field has led to important improvements in progression-free and overall survival in patients with cancer $[26,30]$. Based on our findings and findings of others [7], we agree with the continued use of mTOR inhibitors but suggest close monitoring for treatmentrelated complications. In some cancer patients (i.e., breast cancer) for whom traditional therapies tend to be well tolerated, clinicians should be educated about the toxicities associated with the addition of oral targeted drugs. Risk reduction includes appropriate patient selection, early assessment of toxic effects, and rapid management of serious adverse events [40]. Future large clinical trials with everolimus should study the use of early interventions to prevent known drug-related complications in the hopes of decreasing the incidence of deaths associated with mTOR use.

Despite the size of our analysis, there are several limitations to this study. Data were abstracted from published clinical trial results; therefore, individual patient information was not available. Establishment of clinical or biologic risk factors associated with death while on everolimus was not possible in this analysis. The studies included were conducted by multiple investigators at different institutions; therefore, deaths associated with an adverse event may not have been consistently reported across studies because of subjectivity and disparities in investigator interpretation. At least one FAE was reported in five of the nine RCTs [26, 28, 30-32, 34]. The remaining four RCTs reported no FAEs in either the everolimus or control arms, and this selection may have introduced bias into this analysis [27, 29, 33, 35]. Several studies were not included in this analysis because of lack of adequate $F A E$ reporting with their preliminary data [19-25]. Two studies provided rates of fatal adverse events but did not have absolute numbers that were needed to perform accurate analysis [22, 25]. Final reports on the toxicities related to everolimus may provide more data about the incidence of treatment-related deaths with mTOR inhibitors. Similarly, included studies were conducted at large academic centers in patients with good organ function; consequently, our calculation of incidence of treatment-related mortality may not be generalizable to community practices.

\section{ConCLUSION}

Patients with cancer who receive everolimus are at increased risk of treatment-related mortality. Although the overall incidence remains low, the odds ratio is significant with an increase in the number of patient deaths associated with an adverse event on everolimus therapy compared with control arms. This is clinically relevant given the rapid increase in the widespread use of this mTOR inhibitor to treat multiple types of cancers. Although everolimus has dramatically impacted the outcomes of patients with numerous tumor types, clinicians should be cognizant of these occurrences and should monitor patients closely for drug-related toxicity. The use of everolimus or other mTOR inhibitors will increase in cancer patients as evidence demonstrating their anticancer efficacy continues to be published. Post-approval studies monitoring the potentially lethal side effects of targeted therapies are necessary to best characterize the overall clinical impact of novel agents in oncology patients.

\section{ACKNOWLEDGMENT}

Erin R. Macrae is supported by Translational Grant K12 CA 133250 in experimental therapeutics from the National Cancer Institute.

\section{Author Contributions}

Conception/design: Robert Wesolowski, Mahmoud Abdel-Rasoul, Maryam Lustberg, Charles L. Shapiro, Erin R. Macrae

Collection and/or assembly of data: Robert Wesolowski, Mahmoud AbdelRasoul, Maryam Lustberg, Erin R. Macrae

Data analysis and interpretation: Robert Wesolowski, Mahmoud AbdelRasoul, Maria Paskell, Charles L. Shapiro, Erin R. Macrae

Manuscript writing: Robert Wesolowski, Maryam Lustberg, Maria Paskell, Charles L. Shapiro, Erin R. Macrae

Final approval of manuscript: Robert Wesolowski, Mahmoud Abdel-Rasoul Maryam Lustberg, Maria Paskell, Charles L. Shapiro, Erin R. Macrae

DiscLOSURES

The authors indicated no financial relationships.

\section{REFERENCES}

1. Afinitor (everolimus) tablets for oral administration [prescribing information] (August 2012) East Hanover, NJ: Novartis Pharmaceuticals Corporation.

2. $\mathrm{NCl}$ Guidelines for Investigators. Available at http://ctep.cancer.gov/protocolDevelopment/ electronic_applications/docs/aeguidelines.pdf. Accessed August 4, 2013.

3. Heron M, Hoyert DL, Murphy SL et al. Deaths: Final data for 2006. Natl Vital Stat Rep 2009;57 1-134.

4. Lazarou J, Pomeranz BH, Corey PN. Incidence of adverse drug reactions in hospitalized patients: $A$ meta-analysis of prospective studies. JAMA 1998; 279:1200-1205.

5. Mol L, Koopman M, Ottevanger PB et al. A prospective monitoring of fatal serious adverse events (SAEs) in a Dutch Colorectal Cancer Group (DCCG) phase III trial (CAIRO) in patients with advanced colorectal cancer. Ann Oncol 2010;21: 415-418.
6. Seruga B, Sterling L, Wang L et al. Reporting of serious adverse drug reactions of targeted anticancer agents in pivotal phase III clinical trials. J Clin Oncol 2011;29:174-185.

7. Choueiri TK, Je Y, Sonpavde $G$ et al. Incidence and risk of treatment-related mortality in cancer patients treated with the mammalian target of rapamycin inhibitors. Ann Oncol 2013;24:20922097.

8. Jadad AR, Moore RA, Carroll D et al. Assessing the quality of reports of randomized clinical trials: Is blinding necessary? Control Clin Trials 1996;17: $1-12$.

9. Moher D, Liberati A, Tetzlaff J et al. Preferred reporting items for systematic reviews and metaanalyses: The PRISMA statement. J Clin Epidemiol 2009;62:1006-1012.

10. Cancer Therapy Evaluation Program. Available at http://ctep.cancer.gov/protocolDevelopment/ electronic_applications/ctc.htm. Accessed August 4, 2013.
11. Yusuf S, Peto R, Lewis J et al. Beta blockade during and after myocardial infarction: An overview of the randomized trials. Prog Cardiovasc Dis 1985; 27:335-371.

12. Sweeting MJ, Sutton AJ, Lambert PC. What to add to nothing? Use and avoidance of continuity corrections in meta-analysis of sparse data. Stat Med 2004;23:1351-1375.

13. Bradburn MJ, Deeks JJ, Berlin JA et al. Much ado about nothing: A comparison of the performance of meta-analytical methods with rare events. Stat Med 2007;26:53-77.

14. Higgins JPT, Thompson SG, Deeks JJ et al. Measuring inconsistency in meta-analyses. BM 2003;327:557-560.

15. Harbord RM, Higgins JP. Meta-regression in Stata. Stata J 2008;8:493-519.

16. Begg CB, Mazumdar M. Operating characteristics of a rank correlation test for publication bias. Biometrics 1994;50:1088-1101. 
17. Egger M, Davey Smith G, Schneider M et al Bias in meta-analysis detected by a simple, graphical test. BMJ 1997;315:629-634.

18. Review Manager (RevMan) [computer program]. Version 5.2. Copenhagen, Denmark: The Nordic Cochrane Centre, The Cochrane Collaboration, 2012.

19. Van Cutsem E, Yeh KH, Bang YJ et al. Phase III trial of everolimus (EVE) in previously treated patients with advanced gastric cancer (AGC): GRANITE-1. J Clin Oncol 2012;30(suppl 4):LBA3a.

20. Yardley DA, Bosserman LD, Peacock NW et al. Everolimus with paclitaxel plus bevacizumab as first-line therapy for HER2-negative metastatic breast cancer ( $\mathrm{MBC}$ ): A randomized, double-blind, placebo-controlled phase II trial of the Sarah Cannon Research Institute (SCRI). J Clin Oncol 2012, 30(suppl):108a.

21. Jonasch E, Corn PG, Pagliaro LC et al. Randomized phase II CTEP study of MK2206 versus everolimus in VEGF inhibitor refractory renal cell carcinoma patients. J Clin Oncol 2013; 31(suppl) 4517a.

22. O'Regan R, Ozguroglu M, Andre F et al. Phase III, randomized, double-blind, placebo-controlled multicenter trial of daily everolimus plus weekly trastuzumab and vinorelbine in trastuzumabresistant, advanced breast cancer (BOLERO-3). Clin Oncol 2013; 31(suppl):505a.

23. Bernadou G, Rezai K, Merlin JL et al. Trastuzumab (T) and everolimus (E) pharmacokinetics (PK) in HER2 positive $(+)$ primary breast cancer $(B C)$ patients (pts): Unicancer RADHER trial results. J Clin Oncol 2013; 31(suppl).

24. Ravaud A, Barrios $\mathrm{CH}$, Alekseev BY et al. Randomized phase II study of first-line everolimus plus bevacizumab $(\mathrm{E}+\mathrm{B})$ versus interferon $\alpha$-2a plus bevacizumab $(I+B)$ in patients (pts) with metastatic renal cell carcinoma (mRCC): Record-2 final overall survival (OS) and safety results. J Clin Oncol 2013; 31(suppl):4576a.

25. Motzer RJ, Barrios CH, Kim TM et al. Record-3: Phase II randomized trial comparing sequential firstline everolimus (EVE) and second-line sunitinib (SUN) versus first-line SUN and second-line EVE in patients with metastatic renal cell carcinoma (mRCC). J Clin Oncol 2013; 31(suppl):4504a.

26. Motzer RJ, Escudier B, Oudard S et al. Phase 3 trial of everolimus for metastatic renal cell carcinoma: Final results and analysis of prognostic factors. Cancer 2010;116:4256-4265.

27. Pavel ME, Hainsworth JD, Baudin E et al. Everolimus plus octreotide long-acting repeatable for the treatment of advanced neuroendocrine tumours associated with carcinoid syndrome (RADIANT-2): A randomised, placebo-controlled, phase 3 study. Lancet 2011;378:2005-2012.

28. Yao JC, Shah MH, Ito $\mathrm{T}$ et al. Everolimus for advanced pancreatic neuroendocrine tumors. N Engl J Med 2011;364:514-523.

29. Baselga J, Semiglazov V, van Dam P et al. Phase II randomized study of neoadjuvant everolimus plus letrozole compared with placebo plus letrozole in patients with estrogen receptor-positive breast cancer. J Clin Oncol 2009;27:2630-2637.

30. Baselga J, Campone M, Piccart $M$ et al. Everolimus in postmenopausal hormone-receptorpositive advanced breast cancer. N Engl J Med 2012;366:520-529.

31. von Minckwitz G, Eidtmann H, Loibl S et al. Integrating bevacizumab, everolimus, and lapatinib into current neoadjuvant chemotherapy regimen for primary breast cancer. Safety results of the GeparQuinto trial. Ann Oncol 2011;22:301-306.

32. Huober J, Hanusch C, Fasching PA et al. Neoadjuvant chemotherapy of paclitaxel with or without Rad001: Results of the non-responder part of the GEPARQUINTO study (GBG 44). Cancer Res 2011;71(suppl 3):S3-6.

33. Franz DN, Belousova E, Sparagana $S$ et al Efficacy and safety of everolimus for subependymal giant cell astrocytomas associated with tuberous sclerosis complex (EXIST-1): A multicentre, randomised, placebo-controlled phase 3 trial. Lancet 2013;381:125-132.

34. Bissler JJ, Kingswood JC, Radzikowska E et al Everolimus for angiomyolipoma associated with tuberous sclerosis complex or sporadic lymphangioleiomyomatosis (EXIST-2): A multicentre, randomised, double-blind, placebo-controlled trial. Lancet 2013;381:817-824.

35. Bachelot T, Bourgier C, Cropet $C$ et al. Randomized phase II trial of everolimus in combination with tamoxifen in patients with hormone receptorpositive, human epidermal growth factor receptor 2-negative metastatic breast cancer with prior exposure to aromatase inhibitors: A GINECO study. J Clin Oncol 2012;30:2718-2724.

36. Neuhaus P, Klupp J, Langrehr JM. mTOR inhibitors: An overview. Liver Transpl 2001;7 473-484.

37. Abraham RT. Mammalian target of rapamycin: Immunosuppressive drugs uncover a novel pathway of cytokine receptor signaling. Curr Opin Immunol 1998;10:330-336

38. Cho D, Signoretti S, Regan M et al. The role of mammalian target of rapamycin inhibitors in the treatment of advanced renal cancer. Clin Cancer Res 2007;13(suppl 2):758s-763s.

39. Porta C, Osanto S, Ravaud A et al. Management of adverse events associated with the use of everolimus in patients with advanced renal cell carcinoma. Eur J Cancer 2011;47:1287-1298.

40. Ranpura V, Hapani S, Wu S. Treatment-related mortality with bevacizumab in cancer patients: A meta-analysis. JAMA 2011;305:487-494.

This article is available for continuing medical education credit at CME.TheOncologist.com.

\title{
For Further Reading:
}

Brian M. Wolpin, Kimmie Ng, Andrew X. Zhu et al. Multicenter Phase II Study of Tivozanib (AV-951) and Everolimus (RAD001) for Patients With Refractory, Metastatic Colorectal Cancer. The Oncologist 2013;18:377-378

\begin{abstract}
Background. Treatments that target the vascular endothelial growth factor (VEGF) pathway have efficacy in colorectal cancer. We evaluated tolerability and efficacy of tivozanib (an oral VEGF receptor-1, $-2,-3$ inhibitor) plus everolimus (an oral mammalian target of rapamycin inhibitor).
\end{abstract}

Methods. The phase lb study followed a $3+3$ dose-escalation design with three dose levels. The primary objective in the follow-on phase II study was improvement in 2-month progression-free survival (PFS) from $30 \%$ (historical benchmark) to $50 \%$ in patients with refractory, metastatic colorectal cancer.

Results. Dose-limiting toxicities in the phase lb study were grade 3 fatigue and dehydration. Oral tivozanib (1 mg daily for 3 of 4 weeks) and oral everolimus ( $10 \mathrm{mg}$ daily continuously) were advanced to a 40 -patient phase II study. The most common grade 3-4 adverse events were thrombocytopenia and hypophosphatemia. The 2-month PFS rate was $50 \%$, with 20 of 40 patients having stable disease (SD). Seven (18\%) patients were treated for $\geq 6$ months. Median PFS and overall survival (OS) times were 3.0 months (95\% confidence interval [Cl]: 1.9-3.6 months) and 5.6 months (95\% Cl: 4.4-10.6 months), respectively. Patients who developed grade $1+$ hypertension had increased SD rates (65.2\% vs. $29.4 \%)$ and longer OS times (10.6 vs. 3.7 months).

Conclusions. The oral combination of tivozanib and everolimus was well tolerated, with stable disease achieved in $50 \%$ of patients with refractory, metastatic colorectal cancer. 